\title{
Morphine and remifentanil-induced cardioprotection: its experimental and clinical outcomes
}

\author{
Jin Mo Kim ${ }^{1}$, Young Ho Jang ${ }^{2}$, and Jun Kim² \\ ${ }^{1}$ Department of Anesthesiology and Pain Medicine, School of Medicine, Keimyung University, Daegu, ${ }^{2}$ Institute of Cardiovascular \\ Research, Pusan National University Yangsan Hospital, Yangsan, Korea
}

During the past few decades, a large number of animal studies demonstrated that commonly used opioids could provide cardioprotection against ischemia-reperfusion (I/R) injury. Opioid-induced preconditioning or postconditioning mimics ischemic preconditioning (I-Pre) or ischemic postconditioning (I-Post). Both $\delta$ - and $\kappa$-opioid receptors (OPRs) play a crucial role in opioid-induced cardioprotection (OIC). Down stream signaling effectors of OIC include ATP-sensitive potassium $\left(\mathrm{K}_{\mathrm{ATP}}\right)$ channels, protein kinase C (PKC), tyrosine kinase, phosphatidylinositol-3-kinase (PI3-kinase), extracellular signal regulated kinase1/2 (ERK1/2), glycogen synthase kinase-3 $\beta$ (GSK-3 $\beta$ ), and mitochondrial permeability transition pore (MPTP), among others. Recently, various reports also suggest that opioids could provide cardioprotection in humans. This review will discuss OIC using mostly morphine and remifentanil which are widely used during cardiac anesthesia in addition to the clinical implications of OIC. (Korean J Anesthesiol 2011; 61:358-366)

Key Words: Ischemic postconditioning, Ischemic preconditioning, Morphine, Myocardial ischemia, Myocardial reperfusion, Remifentanil.

\section{Introduction}

It is well-established that ischemic preconditioning (I-Pre) and ischemic postconditioning (I-Post) are explicitly cardioprotective strategies. The signaling pathways of I-Pre and I-Post are becoming increasingly clear. I-Pre, a series of brief ischemia-reperfusion (I/R) cycles before index ischemia, confers resistance against a subsequent prolonged period of myocardial ischemia. The cardioprotective mechanisms of I-Pre involve autacoid factors [1], protein kinase C (PKC) [2], reactive oxygen species [3], reperfusion injury salvage kinases [4],

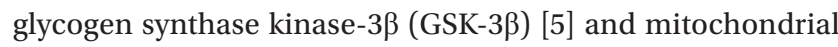
permeability transition pore (MPTP) [6], among others. I-Post, which involves brief episodes of I/R during early reperfusion, is also a powerful strategy to limit reperfusion injury. The cardioprotection by I-Post may share common pathways with I-Pre including recruitment of signal transduction pathways [7]. However, there might be limitations to clinical use of I-Pre and

Received: June 10, 2011. Revised: July 19, 2011. Accepted: July 19, 2011.

Corresponding author: Jin Mo Kim, M.D., Ph.D., Department of Anesthesiology and Pain Medicine, School of Medicine, Keimyung University, 216, Dalseong-ro, Jung-gu, Daegu 700-712, Korea. Tel: 82-53-250-7249, Fax: 82-53-250-7240, E-mail: kimjin00@dsmc.or.kr

(c) This is an open-access article distributed under the terms of the Creative Commons Attribution Non-Commercial License (http:// creativecommons.org/licenses/by-nc/3.0/), which permits unrestricted non-commercial use, distribution, and reproduction in any medium, provided the original work is properly cited. 
I-Post. Indeed, I-Pre depends crucially on intervening before the ischemic event, and it is difficult to predict the onset of acute myocardial infarction. In addition, debates on the precise I-Post algorithm to use in clinical settings are ongoing. In this regard, pharmacological strategies are possible alternative methods and may provide a feasible means of effectively producing cardioprotection clinically. During the last 2 decades, pharmacological preconditioning and postconditioning to reduce myocardial I/R injury have been extensively studied. A number of cardioprotective ligands, including erythropoietin [8], adenosine [9], bradykinin [10], statins [11] and opioids [12], have been identified. Among them opioids are particularly interesting ligands to anesthesiologists because they are widely used during general anesthesia including cardiac anesthesia. In this review, we will discuss the cardioprotective outcomes in animal experiments and human studies that used opioids, particularly morphine and remifentanil which are currently commonly used for cardiac anesthesia.

\section{Evidence of involvement of opioid receptors (OPRs) in I-Pre and I-Post}

After the concept of I-Pre was first described in 1986 by Murry et al. [13], a number of investigators have demonstrated that OPRs are involved in the mechanism of I-Pre-induced cardioprotection. Schultz et al. [14] first reported that OPRs play an important role in I-Pre in rat hearts. The infarct reducing effect by I-Pre elicited by three cycles of 5-min occlusion and reperfusion before $30 \mathrm{~min}$ ischemia was totally blocked by the nonselective OPR antagonist naloxone. One year later, Chien and Van Winkle [15] also demonstrated that the infarct limitation effect by I-Pre was blocked by (-)naloxone hydrochloride intravenously administered 25 min before index ischemia in open-chest rabbits. In addition, Schultz et al. [16] proposed that the cardioprotective effect by I-Pre was mediated by peripheral OPRs. In open-chest rat hearts, a high dose of naloxone methiodide which does not cross the blood-brain barrier antagonized the infarct sparing effect by I-Pre in their study. Taken together, these results strongly suggest that I-Preinduced cardioprotection is likely to be OPR-mediated.

Meanwhile, there is evidence that I-Post-induced cardioprotection also involves the activation of OPRs. Zatta et al. [17] demonstrated that I-Post with 3 cycles of $10 \mathrm{sec}$ reperfusion and $10 \mathrm{sec}$ reocclusion at reperfusion onset increases endogenous cardiac opioids and activates local OPRs in anesthetized rat hearts. In addition, Jang et al. [18] reported that myocardial infarct size could be reduced by I-Post induced by six cycles of $10 \mathrm{sec}$ reperfusion and $10 \mathrm{sec}$ occlusion started immediately after reperfusion in both open and isolated rat hearts. They additionally reported that the infarct-reducing effect by I-Post was totally blocked by naloxone and the $\delta$-OPR antagonist naltrindole. These results highly suggest that endogenous opioid peptides and OPRs are involved in the cardioprotective phenomenon of I-Post.

\section{Opioid peptides and OPRs}

It has been well known that opioid peptide synthesis, storage and release can take place in myocardial cells. Endogenous opioid peptides are synthesized and released after myocardial stres such as hypoxia or ischemia. The three distinct families of endogenous opioid peptides, enkephalins, dynorphins, and endorphins, are derived from three separate prohormones, proenkephalin, prodynorphin, and proopiomelanocortin, respectively. The enkephalins are considered important endogenous opioid peptides responsible for cardioprotection. It has been proposed that the increase in levels of enkephalins in infarcted ventricular tissue may counteract catecholamines released during ischemia and may be a defense mechanism to minimize the size of myocardial infarction [19].

The OPRs have been shown to mediate and regulate cardiovascular system function. OPRs are present centrally (hypothalamus and brainstem) and peripherally (cardiac myocytes, nerve terminals and adrenal medulla). The OPR family comprises three primary subtypes, $\mu_{-}, \delta$-, and $\kappa$-OPRs. Among them, $\delta$ - and $\kappa$-OPRs are present on adult ventricular myocytes of the rat [20], even though $\mu$ - and $\kappa$-OPRs are present in neonatal rat hearts [12]. The $\delta$-OPRs have the highest affinity for enkephalins whereas $\kappa$-OPRs bind preferentially to dynorphins. These OPRs belong to the family of guanine nucleotide binding protein (G-protein)-coupled receptors (GPCRs) which are cell surface proteins that convert extracellular stimuli into cellular signals.

The $\delta$ - and $\kappa$-OPR subtypes include $\delta_{1^{-}}, \delta_{2}$-OPRs and $\kappa_{1^{-}}, \kappa_{2}$-OPRs, respectively. Multiple lines of evidence reveal that $\delta$-OPRs, especially $\delta_{1}$-OPRs, play an important role in cardioprotection [16,21]. Schultz and colleagues [16] suggested that the cardioprotective effect by I-Pre was mediated via $\delta$-OPRs because pre-administered naltrindole completely abolished the cardioprotective effect induced by I-Pre. Furthermore, this group also showed that $\delta_{1}$-OPRs play an important role in the cardioprotection of I-Pre because the selective $\delta_{1}$-OPRs antagonist 7-benzylidenenaltrexone (BNTX) but not the selective $\delta_{2}$-OPRs antagonist naltriben given before I-Pre significantly attenuated the infarct size by I-Pre [21]. I-Post also involves $\delta$-OPR activation because there is evidence that the infarct-reducing effect by I-Post was totally blocked by naltrindole [18], as mentioned above.

Meanwhile, the cardioprotective role of $\kappa$-OPRs is less well characterized than that of $\delta$-OPR and controversy continues 
regarding its role in myocardial I/R injury [21,22]. Schultz et al. [21] tested if the $\kappa$-OPR antagonist nor-binaltorphimine (nor-BNI) administered before I-Pre could block the antiinfarct effect of I-Pre in open-chest rat hearts. The high dose of BNTX significantly attenuated the cardioprotective effect of I-Pre while nor-BNI did not. They demonstrated that $\delta_{1}$-OPRs but not $\kappa$-OPRs play an important role in the cardioprotective effect of I-Pre in the rat heart. Wang et al. [23] proposed that $\kappa$-OPRs mediats the ameliorating effects of I-Pre on infarct and arrhythmia, whereas $\delta$-OPRs mediates the effects only on infarct because nor-BNI but not naltrindole reduced both infarction and arrhythmia in I-Pre with two cycles of 5 min regional ischemia followed by 5 min reperfusion. Taken together, one can not completely rule out a role of $\kappa$-OPRs in cardioprotection.

Meanwhile, the role of $\mu$-OPRs against myocardial I/R remains unclear because results of radioligand binding studies have disputed the presence of $\mu$-OPRs in the myocardium. However, many studies that used morphine, which has a preference for $\mu$-OPRs, showed a successful reperfusion mimetic. Actually, the lower dose of morphine seems to activate $\mu$-OPRs but not $\delta$ - or $\kappa$-OPRs. Weihrauch et al. [24] demonstrated that morphine at reperfusion could reduce myocardial infarct size in rabbit hearts. Zatta et al. [17] suggested that the cardioprotective effect of I-Post appeared to involve endogenously activated $\mu$-OPRs because the infarct sparing-effect by I-Post was abrogated by the potent $\mu$-OPR antagonist CTAP administered at reperfusion in rat hearts. Therefore, it is plausible that $\mu$-OPRs also may be involved in the cardioprotective mechanism.

\section{Exogenous activation of OPRs targeting ischemia}

Over the past decade, accumulating evidence demonstrates that exogenous activation of OPRs confers cardioprotection. Exogenous administration of the naturally occurring opioid peptide Met5-enkephalin via osmotic minipump for $24 \mathrm{~h}$ limits myocardial infarction in anesthetized open-chest rabbits [25]. Schultz's group [26] first reported the cardioprotection by exogenously administered opioid. In their study, the exogenous pre-ischemic administration of morphine in three 5-min infusions interspersed with 5 min morphine-free periods before prolonged coronary occlusion significantly limited infarct size after myocardial I/R in open-chest rat hearts. Fryer et al. [27] demonstrated that exogenous application of the selective $\delta_{1}$ OPRs agonist TAN-67 15 min before index ischemia significantly reduced infarct size in open-chest rats. In addition, there is evidence that exogenous activation of $\delta$ - and $\kappa$-OPRs affords protection against myocardial stunning in isolated murine hearts. The $\delta$-OPRs agonist BW373U86 and the $\kappa$-OPRs agonist U50,488H (trans-( \pm )-3-dichloro- $N$-methy- $N$-[2-(1-pyrrolidinyl) cyclohexyl]benzeneacetamide hydrochloride) administered for 10 min prior to global normothermic ischemia markedly improved post-ischemic contractile recovery as measured by left ventricular developed pressure (LVDP) [28]. Meanwhile, previous studies have demonstrated that exogenous activation of $\kappa$-OPRs with bremazocin increased myocardial infarction and another $\kappa$-OPRs agonist U50,488H exacerbated I/R arrhythmias following coronary occlusion in isolated rat hearts [29]. However, Peart et al. [22] reported that the two different $\kappa$-OPRs agonists U50,488H and ICI204,448 administered 10 min before the onset of ischemia significantly reduced infarct size in a similar extent as $\delta$-OPRs activation by BW373U86. In addition, the $\kappa$-OPRs agonists also reduced arrhythmogenesis in their study. Recently, Maslov et al. [30] reported that peripheral $\delta_{2}$-OPRs activation by deltorphin II induced infarct size reduction in open-chest rat heart which suggests role for $\delta_{2}$-OPRs in cardioprotection. Taken together, these data verify that exogenous $\delta$ - and $\kappa$-ORs activation during ischemia indeed limited myocardial infarction and may improve functional recovery.

\section{Exogenous activation of OPRs targeting reperfusion}

Recently, much research in myocardial I/R injury has shifted the paradigm from ischemic protection to reperfusion-mediated protection because pretreatment is seldom possible in acute myocardial infarction. It has been proposed that exogenous activation of $\delta$-OPRs or $\kappa$-OPRs during the early reperfusion period confers cardioprotection to a similar extent as targeting the ischemic period. Exogenously applied BW373U86 administered 5 min before reperfusion mimicked the effect of I-Post or morphine-induced postconditioning in isolated rat hearts [18]. In addition, the $\delta$-OPRs agonist [D-Ala2, D-Leu5] enkephalin (DADLE) started $5 \mathrm{~min}$ before reperfusion also reduced infarct size in rabbit hearts [31]. Meanwhile, Peart et al. [32] demonstrated that $\kappa$-OPR activation by U50,488H prior to reperfusion affords cardioprotection in both rat and mouse hearts. The infarct-reducing effect by U50,448H administered immediately prior to reperfusion was abolished by nor-BNI, given $10 \mathrm{~min}$ prior to reperfusion. U50,488H perfused $5 \mathrm{~min}$ before reperfusion significantly limited myocardial infarction and its mechanism was mediated by extracellular signal regulated kinase1/2 (ERK1/2) signaling pathway [33].

\section{Morphine-induced cardioprotection in animals}

Over the past decade, accumulating data demonstrate that pharmacological preconditioning and postconditioning with 
commonly used opioids, such as morphine and remifentanil, confer cardioprotection in animals. Morphine is frequently used for pain treatment during acute coronary syndromes. As mentioned above, Schultz's group [26] first reported that morphine-induced preconditioning (M-Pre) mimics I-Pre. Exogenously administered morphine before index ischemia could limit infarct size in rat hearts mediated via $\delta$-OPRs because naltrindole completely abolished the cardioprotective effect induced by morphine [34,35]. M-Pre enhances isofluraneinduced preconditioning in open-chest rat hearts [36]. The downstream signaling pathways of M-Pre involve $\mathrm{K}_{\mathrm{ATP}}$ channels [26,37-39] and PKC [40].

Meanwhile, morphine-induced postconditioning (M-Post) also has a powerful cardioprotective effect, which seems to be similar to M-Pre or I-Post. Gross and co-workers [41] reported that M-Post limited infarct size in I/R-injured rat hearts. This group also demonstrated that the use of morphine and the opioid agonist methadone to manage acute and chronic pain could produce an infarct sparing effect in open-chest rat hearts [42]. Recently, Jang et al. [18] reported that the infarct sparing effect by M-Post was totally blocked by naltrindole in isolated rat hearts, implying the involvement of $\delta$-OPRs in M-Post. More recently, Kim et al. [43] demonstrated that the involvement $\delta_{1}$-ORs in M-Post because the infarct limitation effect by M-Post was totally aborted by BNTX in isolated rat hearts (Fig. 1). Interestingly, however, Chen et al. [44] reported that infarct reducing effects by M-Post in isolated perfused rat

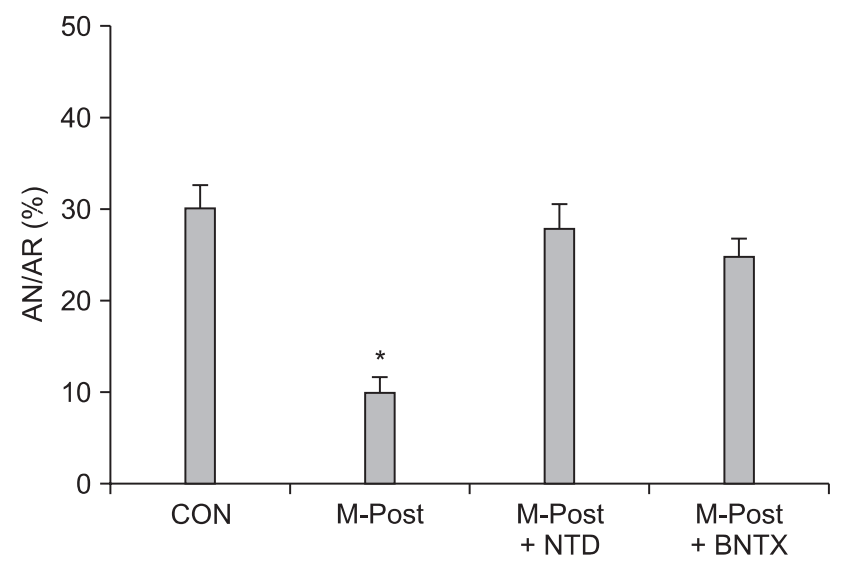

Fig. 1. Evidence for involvement of $\delta_{1}$-opioid receptors in morphineinduced postconditioning (M-Post). Isolated rat hearts were subjected to $30 \mathrm{~min}$ regional ischemia and $120 \mathrm{~min}$ reperfusion. Morphine $(1 \mu \mathrm{M})$ was perfused from $5 \mathrm{~min}$ before reperfusion to 30 min after reperfusion. CON: untreated control hearts, NTD: $\delta$-opioid receptors antagonist naltrindole, BNTX: $\delta_{1}$-opioid receptors antagonist 7-benzylidenenaltrexone. Infarct-limitation effect by M-Post was totally blocked by NTD and BNTX. *P $<0.05$ vs. CON (Modified from Kim et al. [43] with permission). hearts was significantly blocked by nor-BNI but not naltrindole, suggesting involvement of $\kappa$-OPRs but not $\delta$-OPRs in M-Post. In their study, however, OPR antagonists, such as naloxone, naltrindole, and nor-BNI, also limited infarct size. Therefore, their results did not provide a clear distinction as to whether the infarct limitation effect by M-Post was caused by M-Post itself or by OPR antagonists. The proposed signaling mechanisms of M-Post involve nitric oxide [19], $\mathrm{K}_{\mathrm{ATP}}$ channels [44,45], phosphatidylinositol-3-kinase (PI3-kinase) [24], GSK- $\beta[41,46]$, mitochondrial-sensitive potassium channels [12], and MPTP [43]. For more detail on signaling pathways involved in opioidinduced cardioprotection see the reference by Schultz and Gross [47].

\section{Remifentanil-induced cardioprotection in animals}

Remifentanil, the 4-anilidopiperidine derivative of fentanyl, also is a widely used opioid along with morphine during general anesthesia. Zhang et al. [48] first reported that remifentanilinduced preconditioning (R-Pre) reduced myocardial infarct size in open-chest rat hearts. The infarct limiting effect by R-Pre was mediated via $\delta$ - and $\kappa$-OPRs. This group also demonstrated that PKC and mitochondrial $\mathrm{K}_{\mathrm{ATP}}\left(\mathrm{mK}_{\mathrm{ATP}}\right)$ channels play an important role in R-Pre [49]. The cardioprotective mechanisms of R-Pre involve PKC, ERK1/2, and Akt pathways [50-52]. In addition, R-Pre produced delayed cardioprotection in anesthetized rat hearts and this effect was mediated via $\mu$-, $\delta$-, and $\kappa$-OPRs [53]. Furthermore, remifentanil-induced postconditioning (R-Post) also protects I/R induced hearts to a similar extent as I-Post which was mediated by both $\delta$ - and $\kappa$-OPRs [54] while ERK1/2 is involved in R-Post [55]. Meanwhile, remifentanil is a potent ultra short-acting synthetic opioid analgesic drug. Due to its rapid action, extremely short half-life, and rare cumulative effects, remifentanil is usually administered as a continuous infusion clinically. Therefore, it is worthwhile to determine whether remifentanil is protective only during preconditioning and postconditioning or remains protective when given continuously. However, controversy exists about the cardioprotective effect on continuous administration of remifentanil. Kuzume et al. [56] demonstrated that sustained administration of remifentanil before and throughout coronary occlusion did not result in protection of ischemic myocardium in intact rabbit hearts. However, Chun et al. [57] recently reported that continuous infusion of remifentanil targeting both ischemia and reperfusion could reduce infarct size in isolated rat hearts. The reports of pharmacological preconditioning and postconditioning with morphine and remifentanil in an isolated perfused heart, in vivo, in addition to those using cell culture models, are presented in Table 1. 
Table 1. Cardioprotection by Exogenously Applied Morphine and Remifentanil in Animal Studies

\begin{tabular}{|c|c|c|c|}
\hline Opioids & Conditions & Model & Involved OPR subtype(s) and mediators \\
\hline \multirow[t]{7}{*}{ Morphine } & Pre & Intact rat heart & $\delta$-OPRs $[37,41], \mathrm{K}_{\mathrm{ATP}}$ channels [26] \\
\hline & & Intact rabbit heart & $\delta$-OPRs [33], PKC [39] \\
\hline & & Isolated rabbit heart & $\mathrm{mK}_{\mathrm{ATP}}$ channels [36] \\
\hline & & Cardiomyocytes & $\mathrm{K}_{\mathrm{ATP}}$ channels [37], $\delta$-OPRs [38], $\mathrm{mK}_{\mathrm{ATP}}$ channels [38] \\
\hline & Post & Intact rat heart & $\mathrm{K}_{\mathrm{ATP}}$ channels $[40,45], \mathrm{GSK}[40,45], \mathrm{mK}_{\mathrm{ATP}}$ channels [44], mK(Ca) channels [12] \\
\hline & & Isolated rat heart & $\kappa$-OPRs [43], $\delta$-OPRs [18], $\delta_{1}$-OPRs [42], $\mathrm{mK}_{\text {ATP }}$ channels [43], nitric oxide [18], MPTP [42] \\
\hline & & Intact rabbit heart & PI3-kinase [24] \\
\hline \multirow[t]{4}{*}{ Remifentanil } & Pre & Isolated rat heart & $\delta$-OPRs [48], $\kappa$-OPRs [48], PKC [48], $\mathrm{mK}_{\mathrm{ATP}}$ channels [48] \\
\hline & & Intact rat heart & $\mu$-OPRs $[47,52], \delta$-OPRs $[47,52], \kappa$-OPRs $[47,52]$, ERK1/2 [49], PKC [51] \\
\hline & & Cardiomyocytes & Akt [50] \\
\hline & Post & Intact rat heart & $\delta$-OPRs [53], $\kappa$-OPRs [53], ERK1/2 [54] \\
\hline
\end{tabular}

Pre: preconditioning, Post: postconditioning, OPR: opioid receptor, $\mathrm{mK}_{\mathrm{ATP}}$ channels: mitochondrial $\mathrm{K}_{\mathrm{ATP}}$ channels, PKC: protein kinase $\mathrm{C}$, PI3-kinase: phosphatidylinositol-3-OH kinase, $\mathrm{mK}(\mathrm{Ca})$ channels: mitochondrial calcium-sensitive potassium channels, MPTP: mitochondrial permeability transition pore, ERK1/2: extracellular signal-regulated kinases, GSK: glycogen synthase kinase.

\section{Functional recovery by morphine and remi- fetanil against myocardial I/R injury}

Usually, opioids have a negative chronotropic effect, i.e. decreasing heart rate (HR). M-Pre decreases HR after reperfusion in open-chest rat hearts compared to control hearts in open-chest rat hearts [58]. M-Post also decreases HR but has no significant difference in LVDP compared to control hearts [43]. R-Pre results in a decrease in HR, mean arterial blood pressure (MBP), and rate-pressure products (RPP) in openchest rat hearts $[48,52]$ and R-Post and continuous infusion of remifentanil during myocardial I/R also significantly reduces HR [55]. Recently, Chun et al. [57] compared five different remifentanil-based strategies, including R-Pre, R-Post, ischemic targeting remifentanil, reperfusion targeting remifentanil, or both ischemic and reperfusion targeting remifentanil, against myocardial I/R injury. Interestingly, R-Pre better preserved LVDP, which is regarded as a contractility marker of the isolated rat heart, than various other remifentanil-based treatment strategies (Fig. 2). They demonstrated that the reason for that effect might be due to the pharmacology of remifentanil and/ or OPR responses. Namely, continuous infusion of remifentanil targeting only ischemia or only reperfusion may result in OPR desensitization and/or downregulation of OPR sensitization.

Hemodynamic changes after reperfusion by opioids are variously reported according to animal models or ischemic severity. Even in the same experimental animal model with almost identical protocols, the hemodynamic results are occasionally conflicting. For example, Schultz et al. [35] demonstrated that hemodynamic variables obtained for HR, MBP, and RPP by M-Pre were not significantly different compared to untreated control hearts in anesthetized rat hearts. However, another report by this group demonstrated that acute morphine treated-mice hearts showed significant improvement in
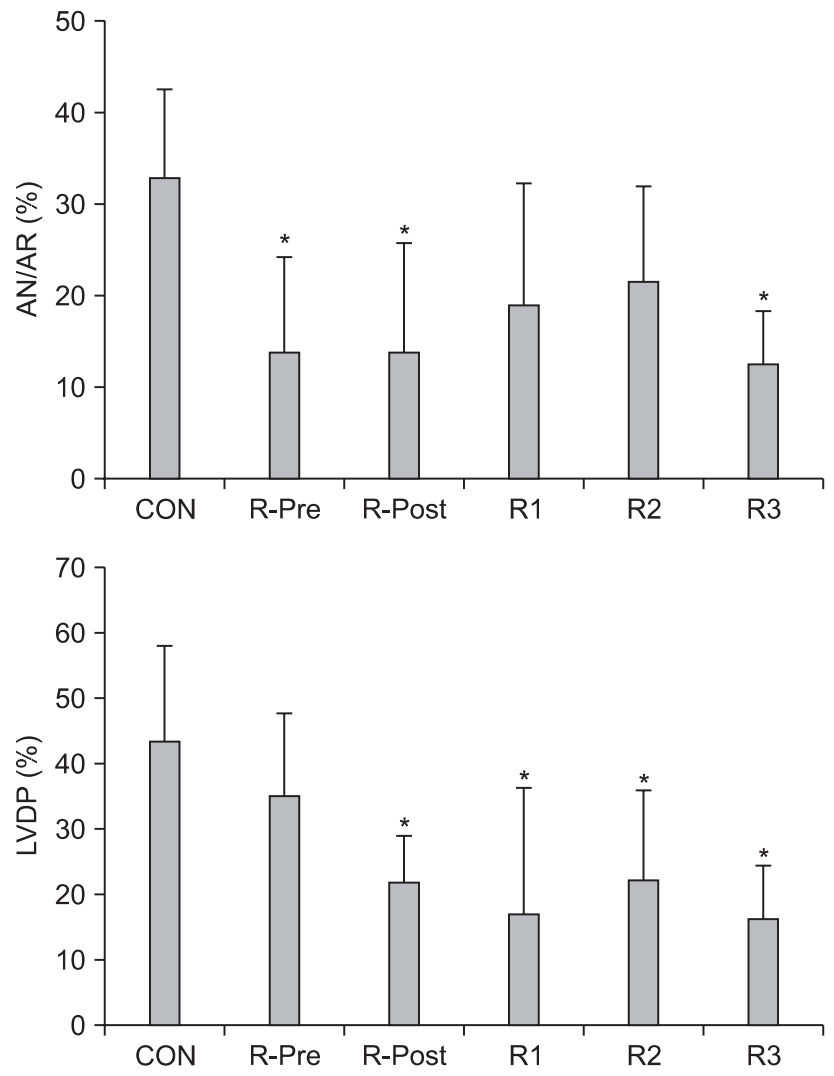

Fig. 2. (Top) Area at necrosis (AN) relative to percentage of area at risk (AR) as evaluated by triphenyltetrazolium chloride staining. (Bottom) Percentage recovery of left ventricular developed pressure (LVDP) after reperfusion in isolated rat hearts. CON: untreated control hearts, R-Pre: remifentanil preconditioning, R-Post: remifentanil postconditioning, $\mathrm{R} 1$ : remifentanil targeting ischemia, R2: remifentanil targeting reperfusion, R3: remifentanil continuous infusion throughout ischemia and reperfusion. $* \mathrm{P}<0.05$ vs. $\mathrm{CON}$ (Modified from Chun et al. [57] with permission). 
recovery of RPP and left ventricular end-diastolic pressure [59].

Infarct size is considered the gold standard measurement for myocardial I/R injury measurement. Functional recovery after reperfusion also is a highly plausible end point and is considered a sensitive one by some authors [60]. However, contractile dysfunction reflects a combination of the effects of stunning and cell death. In addition, the intraventricular balloon may be a less sensitive method for measurement of functional recovery. In this regard, it is suspicious that hemodynamic parameters may accurately reflect cardioprotective effects. Tissue salvaged by an anti-infarct intervention leads to improvement of cardiac function; however, infarct size limitation does not always produce mechanical functional recovery of hearts after myocardial I/R injury. There is evidence that I-Pre and I-Post limit infarct size but do not reduce myocardial dysfunction $[61,62]$. A potent opioid such as fentanyl also reduces infarct size but does not protect against myocardial dysfunction in isolated rat hearts [63]. The discrepancy between infarct size limitation and cardiac function recovery may be explained by continued stunning, i,e. prolonged myocardial dysfunction in the histological absence of necrosis after I/R injury. It is proposed that stunning occurs in reversibly injured cells or via nonlethal injury to the epicardial border zones surrounding infarcted myocardium. Although cellular ATP levels or free radicals have been proposed to be important mediators for stunning [64], the exact mechanism responsible remains unclear. Another possible mechanism for myocardial stunning is an increase in the concentration of intracellular $\mathrm{Ca}^{2+}\left(\left[\mathrm{Ca}^{2+}\right]\right)$. The increase in $\left[\mathrm{Ca}^{2+}\right]$ in myocardial cells likely explains the depressed ability of $\mathrm{I} / \mathrm{R}$ hearts to generate contractile forces.

\section{Cross-talk between OPRs and adenosine receptors (ARs)}

Interestingly, the OPR family is known to 'cross-talk' with other GPCRs families, such as adenosine receptors (ARs). Kato et al. [65] reported that the improvement of post-ischemic mechanical function by fentanyl administered before induction of ischemia was abolished by the selective $A_{1} A R$ antagonist 1,3-dipropyl-8-cyclopentylxanthine (DPCPX) in isolated rat hearts. They suggested the $\delta$-OPR blockade inhibits $A_{1}$ ARsmediated protection. Peart and Gross [66] also demonstrated that there is a functional coupling between OPRs and ARs. The cardioprotection afforded by the $\mathrm{A}_{1}$ ARs agonist 2-chlorocyclopentyladenosine or morphine was abolished by $\delta$-OPRs antagonists BNTX or DPCPX, respectively, in anesthetized rat hearts. Taken together, it is likely that not only morphine but also remifentanil might 'cross talk' with ARs because these opioids activate $\delta$-OPRs. Our recent unpublished data showed that the infarct-limiting effect by R-Post was significantly blocked by both naloxone and the nonspecific AR antagonist 8-(p-Sulfophenyl)theophylline, implying 'cross-talk' between R-Post and ARs in isolated rat hearts. Meanwhile, there also is evidence for 'cross-talk' between OPRs and the $\beta$-adrenergic receptors (ADRs) system in the heart $[67,68]$. For details on 'cross-talk' interactions between OPRs and $\beta$-ADRs in the heart, see the review by Pepe et al. [69].

\section{Morphine- and remifentanil-induced cardio- protection in humans}

As a large number of studies performed in animals and cells strongly revealed that morphine- or remifentanil-induced preconditioning or postconditioning is cardioprotective, it should be determined if a similar effect is seen in the human heart. Growing evidence during recent years suggests that I-Pre and I-Post produce cardioprotection in animal as well as human hearts [70,71]. Tomai et al. [70] assessed whether the OPR antagonist naloxone abolishes adaptation to ischemia in humans during coronary angioplasty after repeated balloon inflations. In naloxone-treated patients, ST-segment change and cardiac pain severity during the second inflation were similar to those observed during the first inflation, whereas in placebo-treated patients, they were significantly lower. This finding reveals that I-Pre is mediated by OPRs in the human heart. Further more, I-Post also protects human hearts. I-Post performed immediately upon closing the lesion with guide wire and consisting of four cycles of $30 \mathrm{sec}$ occlusion followed by $30 \mathrm{sec}$ of reperfusion in patients undergoing primary coronary angioplasty resulted in reduction of infarct size, lower levels of creatine phosphokinase-myocardial band (CK-MB) fraction, and improved ejection fraction [71]. These beneficial effects persisted beyond 3 years. Bell et al. [72] reported that the expression of $\delta$-OPRs in human atrial trabeculae isolated from patients undergoing coronary bypass grafting and $\delta$-OPR stimulation mimicked I-Pre in human heart muscle in an hypoxic-reoxygenation model, which suggests a possible clinical use in myocardial ischemia treatment.

Although many studies with morphine or remifentanil during cardiac procedures have mainly focused on hemodynamics, anesthetic requirement or postoperative analgesics requirement, several interesting reports have been published on a possible pharmacological approach with morphine and remifentanil for the treatment of myocardial ischemia in clinical settings. Murphy and coworkers [73] administered $40 \mathrm{mg}$ of morphine before cardiopulmonary bypass and evaluated the myocardial performance index with echocardiographic parameters intraoperatively. The myocardial performance index was improved by the administration of morphine prior to the ischemic insult of cardioplegic arrest. Pleym et al. [74] reported 
that $0.5 \mu \mathrm{g} / \mathrm{kg} / \mathrm{min}$ remifentanil during coronary artery bypass graft in patients receiving remifentanil-isoflurane anesthesia reduced surgical stress but seemed to cause cardiac depression in the early postoperative phase. The patients who received supplemental remifentanil had a lower cardiac output, left ventricular stroke work index, and mixed venous oxygen saturation than placebo received patients. Recently, however, $\mathrm{Xu}$ et al. [75] reported that R-Pre decreased cardiac troponin I levels in patients undergoing off-pump coronary artery bypass surgery. R-Pre by $5 \mu \mathrm{g} / \mathrm{kg}$ of $10 \mathrm{~min}$ infusion after anesthetic induction markedly decreased the cardiac troponin I levels which is a high-specificity marker for cardiac injury after surgery compared to non-preconditioned patients. In addition, Wong et al. [76] reported that remifentanil administration $1 \mu \mathrm{g} / \mathrm{kg}$ bolus followed by a $0.5 \mu \mathrm{g} / \mathrm{kg} / \mathrm{min}$ infusion for $30 \mathrm{~min}$ after anesthetic induction but before sternotomy yielded lower CK-MB levels in patients undergoing elective on-pump coronary bypass surgery.

\section{Summary}

Morphine or remifentanil has been widely used perioperatively. A large number of in vitro and in vivo studies have demonstrated that morphine or remifentanil reliably offers cardioprotection. Both $\delta$ - and $\kappa$-ORs play a crucial role in morphine- or remifentanil-induced cardioprotection. The signaling pathways involved in the effects of these two opioids are currently being investigated; however, the cardioprotective effects of morphine or remifentanil in human hearts have not been fully examined yet. Further studies are needed to evaluate the effectiveness of morphine and remifentanil in a clinical setting.

\section{References}

1. Yellon DM, Downey JM. Preconditioning myocardium: from cellular physiology to clinical cardiology. Physiol Rev 2003; 83: 1113-51.

2. Ytrehus K, Liu Y, Downey JM. Preconditioning protects ischemic rabbit heart by protein kinase C activation. Am J Physiol 1994; 266: H1145-52.

3. Das DK, Maulik N, Sato M, Ray PS. Reactive oxygen species function as second messenger during ischemic preconditioning of heart. Mol Cell Biochem 1999; 196: 59-67.

4. Hausenloy DJ, Tsang A, Yellon DM. The reperfusion injury salvage kinase pathway: a common target for both ischemic preconditioning and postconditioning. Trends Cardiovasc Med 2005; 15: 69-75.

5. Tong H, Imahashi K, Steenbergen C, Murphy E. Phosphorylation of glycogen synthase-3 $\beta$ during preconditioning through a phosphatidylinositol-3-kinase-dependent pathway is cardioprotective. Cir Res 2002; 90: 377-9.

6. Hausenloy DJ, Maddock HL, Baxter GF, Yellon DM. Inhibiting mitochondrial permeability transition pore opening: a new paradigm for myocardial preconditioning? Cardiovasc Res 2002; 55 : 534-43.

7. Hausenloy DJ, Yellon DM. Survival kinases in ischemic preconditioning and postconditioning. Cardiovasc Res 2006; 70: 240-53.

8. Calvillo L, Latini R, Kajstura J, Leri A, Anversa P, Ghezzi P, et al. Recombinant human erythropoietin protects the myocardium from ischemia-reperfusion injury and promotes beneficial remodeling. Proc Natl Acad Sci U S A 2003; 100: 4802-6.

9. Ban K, Cooper AJ, Samuel S, Bhatti A, Patel M, Izumo S, et al. Phosphatidylinositol 3-kinase gamma is a crucial mediator of myocardial ischemic and adenosine-mediated preconditioning. Circ Res 2008; 103: 643-53.

10. Yoshida H, Kusama Y, Kodani E, Yasutake M, Takano H, Atarashi $\mathrm{H}$, et al. Pharmacological preconditioning with bradykinin affords myocardial protection through NO-dependent mechanisms. Int Heart J 2005; 46: 877-87.

11. Atar S, Ye Y, Lin Y, Freeberg SY, Nishi SP, Rosanio S, et al. Atorvastatininduced cardioprotection is mediated by increasing inducible nitric oxide synthase and consequent S-nitrosylation of cyclooxygenase-2. Am J Physiol Heart Circ Physiol 2006; 290: H1960-8.

12. Huhn R, Heinen A, Weber NC, Schlack W, Preckel B, Hollmann MW. Ischaemic and morphine-induced post-conditioning: impact of $\mathrm{mK}(\mathrm{Ca})$ channels. Br J Anaesth 2010; 105: 589-95.

13. Murry CE, Jennings RB, Reimer KA. Preconditioning with ischemia: a delay of lethal cell injury in ischemic myocardium. Circulation 1986; 74: 1124-36.

14. Schultz JE, Rose E, Yao Z, Gross GJ. Evidence for involvement of opioid receptors in ischemic preconditioning in rat hearts. Am J Physiol 1995; 268: H2157-61.

15. Chien GL, Van Winkle DM. Naloxone blockade of myocardial ischemic preconditioning is stereoselective. J Mol Cell Cardiol 1996; 28: 1895-900.

16. Schultz JJ, Hsu AK, Gross GJ. Ischemic preconditioning is mediated by a peripheral opioid receptor mechanism in the intact rat heart. J Mol Cell Cardiol 1997; 29: 1355-62.

17. Zatta AJ, Kin H, Yoshishige D, Jiang R, Wang N, Reeves JG, et al. Evidence that cardioprotection by postconditioning involves preservation of myocardial opioid content and selective opioid receptor activation. Am J Physiol Heart Circ Physiol 2008; 294: H1444-51.

18. Jang Y, Xi J, Wang H, Mueller RA, Norfleet EA, Xu Z. Postconditioning prevents reperfusion injury by activating delta-opioid receptors. Anesthesiology 2008; 108: 243-50.

19. Paradis P, Dumont M, Bélichard P, Rouleau JL, Lemaire S, BrakierGingras L. Increased preproenkephalin A gene expression in the rat heart after induction of a myocardial infarction. Biochem Cell Biol 1992; 70: 593-8.

20. Krumins SA, Faden AI, Feuerstein G. Opiate binding in rat hearts: modulation of binding after hemorrhagic shock. Biochem Biophys Res Commun 1985; 127: 120-8.

21. Schultz JE, Hsu AK, Gross GJ. Ischemic preconditioning in the intact rat heart is mediated by delta1- but not mu- or kappa-opioid receptors. Circulation 1998; 97: 1282-9.

22. Peart JN, Gross ER, Gross GJ. Effect of exogenous kappa-opioid receptor activation in rat model of myocardial infarction. J Cardiovasc 
Pharmacol 2004; 43: 410-5.

23. Wang GY, Wu S, Pei JM, Yu XC, Wong TM. Kappa- but not deltaopioid receptors mediate effects of ischemic preconditioning on both infarct and arrhythmia in rats. Am J Physiol Heart Circ Physiol 2001; 280: H384-91.

24. Weihrauch D, Krolikowski JG, Bienengraeber M, Kersten JR, Warltier DC, Pagel PS. Morphine enhances isoflurane-induced postconditioning against myocardial infarction: the role of phosphatidylinositiol-3-kinase and opioid receptors in rabbits. Anesth Analg 2005; 101: 942-9.

25. Kuzume K, Wolff RA, Amakawa K, Kuzume K, Van Winkle DM. Sustained exogenous administration of Met5-enkephalin protects against infarction in vivo. Am J Physiol Heart Circ Physiol 2003; 285: H2463-70.

26. Schultz JE, Hsu AK, Gross GJ. Morphine mimics the cardioprotective effect of ischemic preconditioning via a glibenclamide-sensitive mechanism in the rat heart. Circ Res 1996; 78: 1100-4.

27. Fryer RM, Hsu AK, Nagase H, Gross GJ. Opioid-induced cardioprotection against myocardial infarction and arrhythmias: mitochondrial versus sarcolemmal ATP-sensitive potassium channels. J Pharmacol Exp Ther 2000; 294: 451-7.

28. Peart JN, Gross GJ. Exogenous activation of delta- and kappa-opioid receptors affords cardioprotection in isolated murine hearts. Basic Res Cardiol 2004; 99: 29-37.

29. Wong TM, Lee AY, Tai KK. Effects of drugs interacting with opioid receptors during normal perfusion or ischemia and reperfusion in the isolated rat heart-an attempt to identify cardiac opioid receptor subtype(s) involved in arrhythmogenesis. J Mol Cell Cardiol 1990; 22: 1167-75.

30. Maslov LN, Lishmanov YB, Oeltgen PR, Barzakh EI, Krylatov AV, Naryzhnaya NV, et al. Comparative analysis of the cardioprotective proterties of opioid receptor agonists in a rat model of myocardial infarction. Acad Emerg Med 2010; 17: 1239-46.

31. Förster K, Kuno A, Solenkova N, Felix SB, Krieg T. The delta-opioid receptor agonist DADLE at reperfusion protects the heart through activation of pro-survival kinases via EGF receptor transactivation. Am J Physiol Heart Circ Physiol 2007; 293: H1604-8.

32. Peart JN, Gross ER, Reichelt ME, Hsu A, Headrick JP, Gross GJ. Activation of kappa-opioid receptors at reperfusion affords cardioprotection in both rat and mouse hearts. Basic Res Cardiol 2008; 103: 454-63.

33. Kim JH, Jang YH, Chun KJ, Kim J, Park YH, Kim JS, et al. Kappaopioid receptor activation during reperfusion limits myocardial infarction via ERK1/2 activation in isolated rat hearts. Korean J Anesthesiol 2011; 60: 351-6.

34. Okubo S, Tanabe Y, Takeda K, Kitayame M, Kanemitsu S, Kukreja $\mathrm{RC}$, et al. Ischemic preconditioning and morphine attenuate myocardial apoptosis and infarction after ischemia-reperfusion in rabbits: role of delta-opioid receptor. Am J Physiol Heart Crirc Physiol 2004; 287: H1786-91.

35. Schultz JJ, Hsu AK, Gross GJ. Ischemic preconditioning and morphine-induced cardioprotection involve the delta-opioid receptor in the intact rat heart. J Mol Cell Cardiol 1997; 29: 2187-95.

36. Ludwig LM, Patel HH, Gross GJ, Kersten JR, Pagel PS, Warltier DC, et al. Morphine enhances pharmacological preconditioning by isoflurane: role of mitochondrial K(ATP) channels and opioid receptors. Anesthesiology 2003; 98: 705-11.

37. Cohen MV, Yang XM, Liu GS, Heusch G, Downey JM. Acetylcholine, bradykinin, opioids, and phenylephrine, but not adenosine, trigger preconditioning by generating free radicals and opening mitochondrial K(ATP) channels. Circ Res 2001; 89: 273-8.

38. Liang BT, Gross GJ. Direct preconditioning of cardiac myocytes via opioid receptors and KATP channels. Circ Res 1999; 84: 1396-400.

39. McPherson BC, Yao Z. Morphine mimics preconditioning via free radical signals and mitochondrial K(ATP) channels in myocytes. Circulation 2001; 103: 290-5.

40. Miki T, Cohen MV, Downey JM. Opioid receptor contributes to ischemic preconditioning through protein kinase $\mathrm{C}$ activation in rabbits. Mol Cell Biochem 1998; 186: 3-12.

41. Gross ER, Hsu AK, Gross GJ. GSK3 beta inhibition and K(ATP) channel opening mediate acute opioid-induced cardioprotection at reperfusion. Basic Res Cardiol 2007; 102: 341-9.

42. Gross ER, Hsu AK, Gross GJ. Acute methadone treatment reduces myocardial infarct size via the delta-opioid receptor in rats during reperfusion. Anesth Analg 2009; 109: 1395-402.

43. Kim JH, Chun KJ, Park YH, Kim J, Kim JS, Jang YH. Morphineinduced postconditioning modulates mitochondrial permeability transition pore opening via delta-1 opioid receptors activation in isolated rat hearts. Korean J Anesthesiol 2011; 60: 351-6.

44. Chen Z, Li T, Zhang B. Morphine postconditioning protects against reperfusion injury in the isolated rat hearts. J Surg Res 2008; 145: 287-94.

45. Chang WL, Lee SS, Su MJ. Attenuation of post-ischemia reperfusion injury by thaliporphine and morphine in rat hearts. J Biomed Sci 2005; 12: 611-9.

46. Gross ER, Hsu AK, Gross GJ. Opioid-induced cardioprotection occurs via glycogen synthase kinase beta inhibition during reperfusion in intact rat hearts. Circ Res 2004; 94: 960-6.

47. Schultz JE, Gross GJ. Opioids and cardioprotection. Pharmacol Ther 2001; 89: 123-37.

48. Zhang Y, Irwin MG, Wong TM. Remifentanil preconditioning protects against ischemic injury in the intact rat heart. Anesthesiology 2004; 101: 918-23.

49. Zhang Y, Irwin MG, Wong TM, Chen M, Cao CM. Remifentanil preconditioning confers cardioprotection via cardiac kappa- and delta-opioid receptors. Anesthesiology 2005; 102: 371-8.

50. Kim HS, Cho JE, Hwang KC, Shim YH, Lee JH, Kwak YL. Diabetes mellitus mitigates cardioprotective effects of remifentanil preconditioning in ischemia-reperfused rat heart in association with antiapoptotic pathways of survival. Eur J Pharmacol 2010; 628: 132-9.

51. Kim HS, Kim SY, Kwak YL, Hwang KC, Shim YH. Hyperglycemia attenuates myocardial preconditioning of remifentanil. J Surg Res 2011 [in press].

52. Zhang Y, Chen ZW, Girwin M, Wong TM. Remifentanil mimics cardioprotective effect of ischemic preconditioning via protein kinase C activation in open chest of rats. Acta Pharmacol Sin 2005; 26: 546-50.

53. Yu CK, Li YH, Wong GT, Wong TM, Irwin MG. Remifentanil preconditioning confers delayed cardioprotection in the rat. Br J Anaesth 2007; 99: 632-8.

54. Wong GT, Li R, Jiang LL, Irwin MG. Remifentanil post-conditioning attenuates cardiac ischemia-reperfusion injury via kappa or delta 
opioid receptor activation. Acta Anaesthesiol Scand 2010; 54: 510-8. 55. Kim HS, Cho JE, Hong SW, Kim SO, Shim JK, Kwak YL. Remifentanil protects myocardium through activation of anti-apoptotic pathways of survival in ischemia-reperfused rat heart. Physiol Res 2010; 59: 347-56.

56. Kuzume K, Kuzume K, Wolff RA, Chien GL, Van Winkle DM. Remifentanil limits infarct size but attenuates preconditioning-induced infarct limitation. Coron Artery Dis 2004; 15: 449-55.

57. Chun KJ, Park YH, Kim JS, Jang Y, Kim JH, Kim J, et al. Comparison of 5 different remifentanil strategies against myocardial ischemiareperfusion injury. J Cardiothorac Vasc Anesth 2011 [in press].

58. Gross ER, Hsu AK, Gross GJ. The JAK/STAT pathway is essential for opioid-induced cardioprotection: JAK2 as a mediator of STAT3, Akt, and GSK-GSK-3 beta. Am J Physiol Heart Circ Physiol 2006; 291: H827-34.

59. Peart JN, Gross GJ. Cardioprotective effects of acute and chronic opioid treatment are mediated via different signaling pathways. Am J Physiol Heart Circ Physiol 2006; 291: H1746-53.

60. Cave AC, Hearse DJ. Ischaemic preconditioning and contractile function: studies with normothermic and hypothermic global ischaemia. J Mol Cell Cardiol 1992; 24: 1113-23.

61. Jenkins DP, Pugsley WB, Yellon DM. Ischaemic preconditioning in a model of global ischaemia: infarct size limitation, but no reduction of stunning. J Mol Cell Cardiol 1995; 27: 1623-32.

62. Couvreur N, Lucats L, Tissier R, Bize A, Berdeaux A, Ghaleh B. Differential effects of postconditioning on myocardial stunning and infarction: a study in conscious dogs and anesthetized rabbits. Am J Physiol Heart Circ Physiol 2006; 291: H1345-50.

63. Kato R, Foex P. Fentanyl reduces infarction but not stunning via delta opioid receptors and protein kinase $\mathrm{C}$ in rats. Br J Anaesth 2000; 84: 608-14.

64. Kloner RA, DeBoer LW, Darsee JR, Ingwall JS, Hale S, Tumas J, et al. Prolonged abnormalities of myocardium salvaged by reperfusion. Am J Physiol 1981; 241: H591-9.

65. Kato R, Ross S, Foex P. Fentanyl protects the heart against ischaemic injury via opioid receptors, adenosine A1 receptors and K(ATP) channel linked mechanisms in rats. Br J Anaesth 2000; 84: 204-14.

66. Peart JN, Gross GJ. Adenosine and opioid receptor-mediated cardio- protection in the rat: evidence for cross-talk between receptors. Am J Physiol Heart Circ Physiol 2003; 285: H81-9.

67. Xiao RP, Pepe S, Spurgeon HA, Capogrossi MC, Lakatta EG. Opioid peptide receptor stimulation reverses beta-adrenergic effects in rat heart cells. Am J Physiol 1997; 272: H797-805.

68. Pepe S, Xiao RP, Hohl C, Altschuld R, Lakatta EG. 'Cross talk' between opioid peptide and adrenergic receptor signaling in isolated rat heart. Circulation 1997; 95: 2122-9.

69. Pepe S, van den Brink OW, Lakatta EG, Xiao RP. Cross-talk of opioid peptide receptor and beta-adrenergic receptor signalling in the heart. Cardiovasc Res 2004; 63: 414-22.

70. Tomai F, Crea F, Gaspardone A, Versaci F, Ghini AS, Ferri C, et al. Effects of naloxone on myocardial ischemic preconditioning in humans. J Am Coll Cardiol 1999; 33: 1863-9.

71. Garcia S, Henry TD, Wang YL, Chavez IJ, Pedersen WR, Lesser JR, et al. Long-term follow-up of patients undergoing postconditioning during ST-elevation myocardial infarction. J Cardiovasc Transl Res 2011; 4: 92-8.

72. Bell SP, Sack MN, Patel A, Opie LH, Yellon DM. Delta opioid receptor stimulation mimics ischemic preconditioning in human heart muscle. J Am Coll Cardiol 2000; 36: 2296-302.

73. Murphy GS, Szokol JW, Marymont JH, Avram MJ, Vender JS. Opioids and cardioprotection: the impact of morphine and fentanyl on recovery of ventricular function after cardiopulmonary bypass. J Cardiothorac Vasc Anesth 2006; 20: 493-502.

74. Pleym H, Stenseth R, Wiseth R, Karevold A, Dale O. Supplemental remifentanil during coronary artery bypass grafting is followed by a transient postoperative cardiac depression. Acta Anaesthesiol Scand 2004; 48: 1155-62.

75. Xu ZD, Jin M, He WX, Xia SX, Zhao YF, He B, et al. Remifentanil preconditioning lowers cardiac troponin 1 level in patients undergoing off-pump coronary artery bypass graft surgery. Nan Fang Yi Ke Da Xue Xue Bao 2009; 29: 1554-6 [Article in Chinese].

76. Wong GT, Huang Z, Ji S, Irwin MG. Remifentanil reduces the release of biochemical markers of myocardial damage after coronary artery bypass surgery: a randomized trial. J Cardiothorac Vasc Anesth 2010; 24: 790-6. 